\title{
A paternidade: sua significação na vida animal e na vida humana
}

\author{
A. Almeida Júnior
}

A situação juridica toda particular que as leis civis ou penais atribuem ao pai, reconhecendo-lhe certos direitos e impondo-lhe determinados deveres, decorre, evidentemente, das funções biológicas, psicológicas e sociais que desempenha, dentro e fóra da familia, este seu elemento fundamental. De tais funções nem sempre houve conciência muito clara; nem sempre se percebeu que o homem tambem colabora na geração dos filhos, e ainda hoje prevalece a ignorância no tocante ao verdadeiro e imenso alcance da atuação psicológica do pai, quer sobre a vida intelectual e afetiva da criança, quer, por intermédio desta, sobre a complexidade dos acontecimentos sociais. Mas embora muitos pormenores, neste particular, ainda se desconheçam, é já apreciavel a bagagem positiva de informações. Procuraremos, por isso, apresentar um quadro panorâmico do assunto, inclinado a supor, como estamos, que o seu estudo terá efeitos sugestivos benéficos tanto para o legislador como para o jurista.

Como genitor, pesa sobre o pai a grave responsabilidade da constituição biológica do equipamento hereditário dos filhos, em que ele influe não só diretamente, por sua contribuição própria, como tambem indiretamente, pela escolha do componente feminino do casal. E, pois que neste equipamento se condensam, em latência, fatores irremoviveis de todos os atributos do futuro individuo, é bem de ver que ao acerto ou desacerto de sua combinação fica vinculado para 
sempre o destino do descendente. Os legisladores de alguns paizes sabem disto, e diversos, com um açodamento não isento de imprudência, já transportaram para as leis noções de Biologia demasiado recentes para terem essa consagração.

Das capacidades afetivas, intelectuais e morais do pai, da sua cultura, dos recursos do seu trabalho, da continuidade e sabedoria da sua assistência, dependem em grande parte a saude física, o equilibrio mental, o valor produtivo dos filhos, como unidades sociais. A ação psicológica do pai, ação que óra peca por excesso, óra por deficiência, óra ainda por desorientação, - exerce indiscutivelmente, atravez de caminhos já agora menos obscuros, influências de profunda e duradoura repercussão. Graças a ela, asfixia-se no nascedouro ou deixa-se livremente robustecer-se a personalidade de cada filho. Por ela se reforça ou se afrouxa a coesão da família. Com ela, afinal, intervem o pai, quasi sempre sem o saber, no funcionamento do organismo social. De fato, pelas alternativas de atuação no circulo restrito da família, tanto pode o pai impelir o filho para o trabalho honesto como para a delinquência, para a cooperação social como para a rebeldia, para a paz como para a guerra.

Cada homem é, pois, atravez das funções da paternidade, um co-responsavel na história do seu paiz e na evolução da humanidade. Co-responsavel minúsculo, é verdade, si considerado isoladamente; mas poderoso e decisivo quando encarado no conjunto total das sociedades distribuidas pelo tempo e pelo espaço.

Depois de atingido um certo grau de cultura, houve sempre noção destas coisas. Por isso mesmo, leis, usos e costumes de cada povo não têm esquecido de disciplinar as funções da paternidade, fixando os direitos e os deveres dos pais em relação à prole. Mas é inegavel que direitos e deveres vêm variando de amplitude de uma época para outra e de um para outro paiz, de acordo com as concepções sociais e os interesses dominantes. Compare-se, por exemplo, a situação do "pater familias" do direito romano, todo poderoso em relação aos filhos, com a do pai brasileiro de hoje, 
cheio de deveres e, ao mesmo tempo, tutelado pelo Estado nos seus atos essenciais referentes a prole. Veja-se depois o pai norte-americano, mais distanciado ainda do "pater familias", e cujos filhos, quando querem casar-se, nem siquer o consultam sobre a escolha da noiva (1). E com ambos se confronte, afinal, o pai da Rússia soviética, assessorado a cada instante pelo Órgão de Tutela e Curatela, que pode intervir até mesmo na escolha do nome da criança.

Será de se prever, diante disto, e convirá aos interesses humanos, em face do que ensina a ciência, uma alteração fundamental nas relações entre pais e filhos, uma organização, por exemplo, como a que nos promete o sr. LÉon BLUM, para quem "o ato mais importante da vida de Rousseau foi talvez o de ter engeitado na roda os filhos nascidos de Tereza" (2)? Daí para a solução proposta por Platão e realizada pelas formigas, em que a familia desaparece, em que o pai é apenas um reprodutor selecionado, não dista praticamente quasi nada.

Para avaliar-se a situação estratégica do pai na vida social, basta observar que as suas funções são quasi sempre a arma cubiçada pelos reformadores da sociedade, e que a proposito delas se degladiam, de uma parte, os que julgam indispensavel o instituto da familia, e de outra, os que supõem esse instituto vantajosamente substituivel por aparelhos de assistência e orientação coletivas.

As justificativas de base cientifica em favor desta ou daquela concepção referente às funções paternas, são procuradas, de regra, no estudo das sociedades animais, no das sociedades humanas primitivas e na Psicologia social. O território desses conhecimentos, ainda mal policiado, permite grandes liberdades de imaginação, de que têm sido vitimas prediletas a psicologia e as organizações familiares animais. Ultimamente, porém, uma reação critica se fez, no sentido

(1) Brockelbank (W. J.) - La Formation du Mariage dans le Druit des Etats-Unis, Paris, 1935, pag. 241.

(2) LÉON BLUM - Du Mariage, Paris, 1937, 112.a edição, pg. 318. 
de dar alguma ordem ao assunto, e, desse modo, tornar mais seguro o seu exame. Sem prejulgarmos da legitimidade da exploração de todos esses dominios, como fontes de argumentos e sugestões idôneas em favor de qualquer teoria a respeito da função do pai na familia humana, passaremos em rápida revista, neste primeiro trabalho, os fatos essenciais relativos à paternidade entre os animais, reservando para trabalhos posteriores o estudo da paternidade humana e o da psicologia da paternidade.

\section{A PATERNIDADE ENTRE OS ANIMAIS}

\section{0 método comparativo}

Querendo justificar-se por ter ido buscar nas sociedades animais as bases da sociedade humana, Alfred Foulllée se apoia em Aristoteles, Buffon e Augusto Comte. "Os que procuram aprofundar as questões relativas à natureza do espírito, cometem o erro de não se ocupar sinão da alma do homem", escreveu o primeiro. "Si o homem não fosse comparavel", disse Buffon "não seria inteligivel". Quanto ao chefe da escola filosófica positivista, mais de uma vez censurou os psicólogos e sobretudo os ideólogos, por se absterem do estudo da vida animal (3).

$O$ confronto entre os animais e o homem não implica, como se poderá supor, um prejulgamento de sentido evolucionista. A Anatomia comparada teve suas bases lançadas por Cuvier, o "inimigo numero um do evolucionismo. A Fisiologia e a Psicologia comparadas vêm sendo exploradi.s tanto pelos que aceitam a doutrina da evolução, - isto é, pela quasi totalidade dos cientistas atuais, - como pelos que a recusam. Comparar não significa filiar nem explicar: "comparaison n'est pas raison". Mas a comparação, mesmo de seres que não se aparentam entre si, tem a inestima-

(3) Alfred Fouillée - Les Éléments Sociologiques de la Morale, 2.' edição, Paris, 1905, pags. 110 e 111. 
vel vantagem de aguçar a curiosidade: a inteligência humana gosta de comparar, mórmente quando um dos termos da comparação é o próprio homem. Graças a esse processo, fixa-se mais demoradamente a atenção sobre os fatos que se estudam, salientam-se semelhanças e diferenças, põem-se mesmo em evidência caractéres não notados anteriormente. Por isso, seja qual for o ponto de vista em que nos coloquemos, o estudo comparativo dos fatos comuns ao homem e aos animais é perfeitamente legitimo e altamente recomendavel.

No tocante à psicologia e à sociologia, o método da comparação levou, na segunda metade do século passado e nos principios deste século, a exageros perniciosos e ridículos. Mas por defeito de execução. Foi moda, entre naturalistas e sociológos, situar no mesmo plano e explicar por causas idênticas, os dois grupos de fenómenos: de um lado, os da psicologia e sociologia animais; de outro, os da psicologia e sociologia humanas; convertendo aqueles em uma caricatura fantasista destes.

Três circunstâncias concorreram para o êrro. Em primeiro logar, numa época de apaixonado darvinismo, a febre de preencher de qualquer forma, em todos os domínios, a arvore genealógica da evolução: era preciso achar, do protozoário ao homem, custasse o que custasse, germes mais ou menos desenvolvidos de todos os órgãos e funções.

Depois, a pobreza de documentação realmente científica. Na falta de verificações sistemáticas e precisas, naturalistas, psicólogos e sociólogos manipulavam as anedotas contadas por observadores superficiais e imaginosos, como os caçadores, ou as lendas colhidas da boca dos indígenas pelos viajantes.

Por fim, a tendencia à explicação antropomórfica. $\mathrm{O}$ vício vinha de Aristóteles e fora agravado desmesuradamente por Plínio (4). Demais, a ausência de documentação exata soltava as rédeas à imaginação: amor materno, amor filial, prudència, astúcia, hipocrisia, gratidão, devotamento, altruismo, magnanimidade eram distribuidos discre- 
cionariamente aos animais, de acor̃do com as fábulas, o folclore ou com a mera simpatia dos criadores benévolos. Pois não chega um dos mais argutos na materia, EspinAs, a considerar a colmeia "um organismo moral", atribuindo-lhe "conciência" e "esperanças comuns"? e a explicar o vinculo conjugal das aves monogâmicas por fatores "intelectuais" (5) ?

Por outro lado, houve pressa em descobrir nas sociedades animais inspirações para a organização da vida social humana, ou para a defesa das instituições já existentes. Os amigos da monogamia achavam, entre aquelas, exemplos deste regime, com tais primores de fidelidade conjugal que os bichos viuvos preferiam o suicídio a um novo casamento. Aos adversários, porém, of ereciam-se, mais faceis ainda, amostras de aves e macacos em escandalosa e convidativa poligamia. Westermack "versus" Briffaut! Como si o fato de uma certa organização familiar encontrar-se em algumas espécies animais, - ou mesmo em todas, - fosse argumento suficiente para que o homem, na complexidade da

(4) Aristóteles escrevera: “Os animais têm naturalmente certa faculdade de participar de todas as afecções que a alma pode experimentar (Historia dos Animais, Liv. IX, cap. 1, n. 1). Segundo ele, camelos e cavalos têm horror ao incesto. Um camelo forçado, por fráude, a esse ato, matou a dentadas o tratador. O cavalo do rei de Citia, induzido ao incesto pelo mesmo processo, suicidou-se por precipitação. (Ib. Cap. XXXIV. n. 1).

A História Natural de Plínio é rica de informações anedóticas, dadas como verdadeiras. O elefante experimenta a paixão do amor e da glória; possue, em grau raro mesmo no homem, a honestidade, a prudência, a justiça. Quando os elefantes domesticados devem atravessar o mar, não embarcam nos navios sem que previamente o condutor lhes prometa o regresso, sob juramento. (Livro VIII, 1, 2). Um elefante um pouco duro de cabeça, tendo sido diversas vezes açoitado porque não aprendia depressa certas habilidades, foi visto (o fato é certo, diz Plínio), repetindo a lição durante a noite (Ibid., $I I I, 1)$. O leão reconhece pelo olfato o adultério cometido pela leôa com o leopardo, e se vinga violentamente; por isso, a leôa depois dessa falta se lava no rio e não segue o leão sinão de longe (Ibid. $X V I I, 2)$. O hipopótamo, quando se sente doente por excesso de nutrição, procura um caniço aguçado, apoia-se nele e pratica em si próprio uma sangria $(I b . X L, 1)$.

(5) Espinas (Alfred) - Des Sociétes Animales, 3.a ed., Paris, 1924 , pags. 295 e 343. 
sua vida civilizada, devesse copiá-la. "Não ha sinão puerilidade nas divagações de um Toussenel, nas fantasias de um Forel, entusiasta das castas, que, para alicerçar suas convicções socialistas, desejaria transformar o homem em inseto. Irá o homem instituir a poligamia para macaquear os macacos, restabelecer a escravidão em homenagem às formigas, desvirilizar seus militares por amor aos termitas? 0 homem deve procurar suas regras de vida social em sua própria natureza, e não em outra parte" (6).

A reação em favor dos métodos objetivos, no estudo da conduta animal, teve como causa remota, aparentemente, as verificações de Johannes Muller, nos começos do século XIX, mostrando grandes diferenças morfológicas e funcionais entre o sistema nervoso dos animais inferiores e o dos animais superiores, noção que, embora não deva exagerarse, dá azo à suspeita de que os tipos de reações de uns e outros devem igualmente distanciar-se. Iniciadas com LoEB, em 1890, as pesquizas proseguiram nas mãos de THORNDIKE, Lloyd Morgan, Jennings, Wheeler, Koeller, Yerkes, BuyTENdiJK, Alverdes, Zuckermann e inumeros outros. As informações se tornaram, com isso, mais escassas e menos pitorescas do que no tempo das anedotas; mas o que perderam em quantidade e graça, ganharam em segurança científica.

\section{Modalidades na relação biológica de paternidade}

Pai, no sentido estritamente biológico, é o genitor masculino, o fornecedor do espermatozóide. Condições diversas obrigam, porém, a agregar a essa noção nuclear alguns outros elementos, que já agora, quando nos referimos à vida humana, integram o conceito de paternidade. O pai é, adicionalmente, quem abriga, defende, alimenta e educa; ou, numa palavra, o protetor. Destas cinco funções elementa-

(6) Picard (Françors) - Les Phénomènes Sociaux chez les Animaux, Paris, 1933, pag. 189. 
res, contidas no sentido amplo da paternidade humana, quais as que encontram raizes nas manifestações da vida animal? quais as decorrentes da situação "sui generis" do homem, na serie biológica, ou dos artifícios da sua estruturação social? Talvez possamos averiguá-lo, atravez do nosso estudo. Começemos por examinar, do protozoário ao homem, as diferentes modalidades na relação biológica de paternidade e filiação.

Ha animais que não têm, que nunca tiveram pai nem mãe. Um paramécio (para citar exemplo vulgar), um animalzinho unicelular, microscópico, cuja vida JENNings acompanhou carinhosamente (7), alimenta-se, cresce, e um belo dia se divide em dois. Dois filhos, evidentemente. Mas com o nascimento destes, o paramécio originário desaparece, pois o seu corpo se reparte entre os dois filhos. 0 paramécio é, pois, órfão por natureza.

Ha animais que só têm mãe. É o velho caso da partenogênese, bem conhecido nas abelhas, mas encontradiço tambem nas plantas e em diversos animais inferiores: pulgões, carrapatos de cobra, rotíferos, cladóceros, afídios. Os filhos podem nascer, - e frequentemente nascem - sem a colaboração do genitor masculino. Nesse sentido, o que a natureza faz espontaneamente em alguns animais, o homem tem conseguido provocar artificialmente em outros, - no bicho da seda, no ouriço do mar, na estrêla do mar e até na rã, submetendo os respectivos óvulos a excitantes mecânicos ou químicos. Deve ser este o caminho para a longinqua realização do sonho de Augusto Comte, a "utopia feminina", isto é, a geração humana sem o concurso do homem (8).

Encontramos, por outro lado, animais que, em relação a cada filho, são ao mesmo tempo pai e mãe. Acontece isso,

(7) Jennings (H. S.) - Vie et Mort, Hérédité et Évolution chez les organismes unicellulaires; trad. francesa, 1931. A fertilização recíproca dos paramêcios e outros protozoários, precursora da reprodução sexual, foi verificada por Maupas, no século passado.

(8) Comte (Augusto) - Système de Politique Positive, Paris, 1854, IV vol., pags. 198 e 319. 
por exemplo, com a incômoda tenia solitaria, parasita do intestino humano: o mesmo individuo, que é hermafrodita, produz óvulos e espermatozóides, conjugados por auto-fecundação. Mais comum, porem, entre os hermafroditas, é a fecundação recíproca: na união sexual, um indivíduo fertiliza o outro e é por este fertilizado; de sorte que o mesmo animal é pai de alguns filhos e mãe de outros. Ainda no grupo dos hermafroditas, ha o curioso caso de animais como certos isópodos, que, quando jovens, são machos, e, quando mais avançados em idade, por involução dos órgãos masculinos se tornam femeas: são, portanto, pais na mocidade, mães na velhice.

Mas à medida que a organização se complica, a reprodução se vai tornando francamente bi-sexual, com indivíduos distintos para um e outro sexo. Cada genitor será exclusivamente pai ou mãe; cada filho terá invariavelmente dois genitores.

\section{O que significa o advento do pai}

Muitos seres, como se viu, nascem sem a colaboração de um pai; outros ha, ao contrário, cuja existência depende da intervenção do reprodutor masculino.

É vantajosa para a espécie a complicação decorrente do aparecimento do pai? Em outros termos: convem a reprodução sexual? Étienne Rabaud julga que não, pois não consegue descobrir, no processo, nenhuma superioridade sobre a reprodução agâmica. $O$ aumento de fertilidade obtido pelo cruzamento de dois individuos, - si existe, - é insignificante e está longe de compensar uma evidente desvantagem: a necessidade, para a reprodução, do encontro de dois seres de sexo oposto, o que, em determinadas circunstâncias, pode constituir obstáculo à propagação da espécie (9).

(9) Rabaud (Étienne) - Éléments de Biologie Générale, 2.a ed., Paris, 1928, pag. 220. 
Predomina, porém, entre os biologistas, o parecer contrário: a reprodução gâmica é vantajosa, e por varios argumentos:

1 Ha economia de substância viva: grande numero de individuos podem nascer, ao mesmo tempo, de um casal de genitores, sem sacrifício apreciavel do corpo destes.

2. Nos seres de reprodução gâmica, o plasma germinativo, de onde provêm os gametos, fica mais ou menos isolado do resto do corpo, do "soma", e, portanto, preservado dos agentes nocivos que sobre este incidem. Assegura-se melhor, assim, a normalidade da descendência.

3. Cada genitor fornece ao descendente uma coleção completa de fatores ou "gens" para todos os seus atributos somáticos e funcionais. O filho recebe, pois, para cada futuro carater, um par de fatores, em que um elemento é de origem paterna, e o outro, de origem materna. Como na coleção vinda de cada genitor ha, frequentemente, gens defeituosos, e é pouco provavel que os defeitos, numa e noutra coleção, se localizem em gens do mesmo par (especialmente si os genitores não são parentes próximos), as falhas porventura legadas por um dos pais serão corrigidas pela contribuição do outro.

4. Na reprodução sexual, o descendente é, originariamente, igual ou quasi igual ao ascendente; as variações que existem entre os indivíduos dependem sobretudo do ambiente. Na reprodução sexual, na reprodução em que ha pai e mãe, tais variações resultam tambem das novas combinações genéticas (mixovariações). "A produção de indivíduos "únicos" parece ser o principal propósito da reprodução sexual" (10).

5. Nas espécies animais elevadas, em que a longura da infância exige cuidados assiduos de proteção, a duplicidade

(10) Conklin (Edwin Grant) - Heredity and Environment, 6. ${ }^{\text {a }}$ ed., Princeton, 1930, pag. 176. 
sexual corresponde a uma vantajosa divisão de trabalho: o genitor feminino se incumbe da proteção intima (alimentação, cuidados pessoais), cabendo ao genitor masculino a proteção periférica (defesa, procura de recursos).

6. A colaboração biológica torna necessario que, para a união conjugal, o indivíduo de um sexo escolha o companheiro do outro sexo. Esta escolha determina, por via da "seleção sexual", a eliminação dos mal dotados, dos doentes graves, dos defeituosos, - com evidente benefício para a prole.

7 A diferenciação sexual tornou-se, na espécie humana, a base de um sentimento poderoso, - o amor, - cujos impulsos, sublimados pela civilização, têm sido a força mais eficiente no estímulo às produções artísticas e científicas, às atividades sociais, aos atos de generosidade, de altruismo, -a tudo, enfim, que embeleza a vida.

Destas singelas considerações, estritamente biológicas, poderiamos extrair, - si fosse ainda necessário, - algumas aplicações para a vida humana. A "utopia feminina" de Augusto Comte não lograria, por nenhuma forma, o sufrágio dos biologistas, em vista das razões com que defendem a mixovariação. Não alcançariam tampouco o seu apôio os casamentos de consaguineos, em que a possibilidade da correção dos gens, uns pelos outros, desapareceria. E seria condenada, por lhe faltar o estímulo gerador das grandes atividades humanas, qualquer tipo de matrimônio que procurasse unir e vincular os individuos entre si, não pelo amor, mas pela coerção legal ou qualquer outra força de origem externa.

\section{O pai entre os invertebrados}

Não ha grave paradoxo em dizer-se que os animais pluricelulares, de reprodução gâmica, nascem duas vezes: primeiro, quando, pela conjugação dos gametos, se forma o ovo; depois, quando o envólucro do ovo se rompe. A cada um 
destes dois "nascimentos" sucede um periodo em que o novo ser precisa de proteção mais ou menos assidua por parte dos adultos: o período da incubação e o período da infância.

Ha animais que não cuidam dos filhos nem durante a incubação nem na infância. A regra vale sobretudo para os invertebrados. Ainda assim, não é raro encontrar-se entre eles, não a proteção "atual", mas uma espécie de proteção preventiva. A mosca doméstica deposita os ovos em sítio onde a futura larva, deficiente em meios de locomoção, possa encontrar com fartura o alimento. "Cerceris arenaria" "Sphex flavipennis", e outros insetos observados por FABRE (11), praticam atos de proteção preventiva ainda mais complicados. A cooperação do pai, neste caso, é quasi sempre nula. Uma das raras exceções está no "geotrupo estercorario", coleóptero em que o macho auxilia a fêmea na feitura do niho e no armazenamento de provisões para as larvas.

O "geotrupo estercorario" representa, na opinião de FABRE, o primeiro ensáio, na escala zoológica, para a organização de uma familia comparavel à do homem. "O encontro de um instante se transforma em associação duravel. A vida matrimonial, o lar se funda: soberba inovação, da qual vamos achar o primeiro ensáio em um estercorário" (12). Exemplos semelhantes, mas de cooperação ainda menos ativa, mostram outros tres coleópteros: "Sisyphus", "Copris lunaris" e "Onitis Bison"

Si a sociedade é "comunista", ha uma proteção conjunta, em favor da geração nova, pela coletividade. É o que acontece com as formigas, os termitas e as abelhas de vida social. Mas, - fato importantissimo, - neste caso a sociedade está, do ponto de vista da capacidade genética, dividida em dois grupos: os reprodutores, que são a minoria, e os

(11) Fabre (J. H.) - Souvenirs Entomologiques, ed. definitiva ilustrada, 10 vols., Paris, 1925. Convem notar que observadores mais recentes "e mais críticos" põem em dúvida a exatidão das descricões de Fabre (M. Golds mith, La Psychologie Comparée, Paris, 1927, pag. 211).

(12) FABRE (J. H.) - Op. cit. vol. r, pag. 207. 
neutros, praticamente assexuados que constituem a imensa maioria. É à custa dessa diferenciação, decorrente de uma verdadeira castração biológica da maioria, que os genitores podem ficar dispensados da tarefa de criar os próprios filhos, entregues estes à proteção coletiva.

Entre os insetos e demais artrópodos, o macho representa o "sexo fraco", morfológica e funcionalmente. Como pai, salvo minguadas exceções, seu papel se limita a fornecer o espermatozóide. "Uma vez celebradas as nupcias, é um incapaz, um ocioso, um inutil, uma superfluidade" (13). Superfluidade que, em algumas espécies, as proprias femeas ou as obreiras se encarregam de destruir. Isto acontece, por exemplo, com o escorpião, cujo fim trágico é descrito pelos entomologistas: após o ato sexual, longo de varias horas, o macho, já agora imprestavel, é agarrado pela fêmea e por ela devorado friamente. O macho de certas aranhas precisa, para escapar de destino semelhante, por-se a salvo imediatamente depois de haver cumprido o seu dever de genitor. Nas colmeias, quando o rigor da estação obriga a uma temporada de reclusão e aconselha a reduzir o numero de bocas inuteis, os machos são expulsos e morrem ao relento, de frio e de inanição. Outro tanto se dá com as formigas: "Logo que o período de união sexual (cuja duração não é sinão de algumas horas) está terminado, e o bando regressou para o interior da terra, os infelizes maridos, incapazes de prover à sua subsistência, perecem miseravelmente" (14').

E reduzida, pois, nos invertebrados, a proteção da geração adulta em favor da nova geração, e quando existe, cabe a outros que não o pai : cabe à mãe ou às obreiras. A deficiência de proteção se compensa, porém, por dois fenómenos biológicos: de um lado, a curta duração da infância do animal, o que lhe permite tornar-se rapidamente capaz de prover à sua própria subsistência; de outro lado, a enorme

(13) Fabre (J. H.) - Op. cit. vol. V, pag. 207.

(14) Buchner (L.) - La Vie Psychique des Bêtes, trad. fr. de Ch. Letourneau, 1881, pag. 85. 
prolificidade dos invertebrados, circunstância esta que atenua, para a espécie, o prejuizo da grande destruição de ovos e de larvas.

Onde, como entre os insetos sociais, a uma grande produção de ovos se associa um serviço organizado de assistência aos filhos, o numero absoluto de individuos alcança totais imensos, e a espécie influe decididamente sobre a vida geral do globo. Ha certos logares do nosso planeta, declarou Wheeler, em que o homem é quem governa; mas outros ha em que é a formiga que manda.

\section{O pai entre os peixes, anfíbios e répteis}

O "pai" peixe surge subitamente no cenário biológico, com quasi todos os atributos do "pai" humano; mas se revela tão excessivo no desempenho das funções protetoras, que o outro elemento do casal, a mãe, fica sem serviço.

E celebre o "Chromis pater familias", do lago das Tiberiades, que abriga mais de cem alevinos na boca e na cavidade branquial. Um peixinho litoreano, "Gobius minutus", se recolhe sob uma concha de molusco invertida, e aí fica à espera de uma fêmea; esta vem, põe os ovos por baixo da concha e retira-se para não mais voltar; o macho fecunda os ovos e permanece vigilante ao lado deles.

Mais curioso ainda é o "epinóquio", pequeno peixe armado de espinhos, que habita as aguas doces e salgadas da Europa e da América do Norte. Com algas e hervas aquáticas, o macho, ainda solteiro, fabrica cuidadosamente o ninho para a prole eventual. Depois, parte em busca de uma fêmea em condições de ser mãe dos seus futuros filhos; e, encontrando-a, condú-la ao abrigo que preparou. A mâe, cumprida a sua missão estritamente biológica, abandona o lar e a ninhada; mas o macho aí fica, à porta do ninho, paciente e atento na proteção dos ovos. $O$ epinóquio é, como se vê, o mais paternal de todos os peixes: "para ele, a pa- 
ternidade é uma verdadeira paixão" E nem por isso deixa de ser valente e belicoso. "No campo de batalha, um guerreiro; no seio da família, uma mãe" (15).

Tambem os anfíbios, filogeneticamente descendentes dos peixes, apresentam alguns exemplos, embora raros, de deJir ạão paternal. O mais típico é o do "sapo parteiro". " fêmea põe os ovos dispostos em um cordão gelatinoso; o macho se apodera do cordão, enrola-o em torno das patas trazeiras e o carrega consigo até o momento da eclosão.

Mas comparemos agora, antes de novo assunto, os dois processos opostos praticados pelos anfíbios com o fim de assegurar a persistência das espécies. Confrontemos, por exemplo, o sapo parteiro com o sapo vulgar. A fêmea do sapo parteiro põe, de cada vez, uma ninhada escassa, trinta ou quarenta ovos, que o macho protege cuidadosamente. A fêmea do sapo vulgar põe uma ninhada enorme, de até sete mil ovos, e os abandona friamente ao seu destino. Este último é o processo anti-econômico, que consiste em produzir muito e não olhar a desperdícios; aquele é, por certo, o processo econômico, que manda produzir pouco, mas poupar. O exemplo do sapo parteiro irá ganhando adeptos, atravez da progressão evolutiva das espécies, e, com as devidas adaptações, será dado como paradigma à própria espécie humana.

Na classe dos répteis, uma circunstância nova vem contribuir para que estes deselegantes vertebrados possam continuar a ser pais pouco solícitos, como os anfíbios, mas não se vejam obrigados a imitar a estes, na profusão de ovos. A formação de uma casca calcárea ou papirácea em torno do ovo não sómente o poupa a uma evaporação muito rápida, como tambem o coloca a salvo dos inimigos menos robustos. Os répteis põem, de fato, poucos ovos: dois a cento e cincoenta em cada ninhada. Si à proteção automática da casca acrescentarmos a facilidade da incubação, que não exige

(15) Menault (ERnest) - L'Amour maternel chez les Animaux, Paris, 1901, 2." ed., pag. 66. 
temperatura elevada nem constante, e si notarmos que o periodo da infância praticamente não existe na classe, teremos registrado uma série de fatores mais do que suficientes para dispensarem os répteis da sujeição conjugal e da dedicação paterna. Prevalecendo-se disto, eles são, na realidade, maridos infieis e pais indiferentes.

\section{O pai na classe das aves}

A correlação inversa entre a prolificidade da espécie e a eficácia dos meios de proteção à descendência, confirmase ainda uma vez pelo que se observa nas aves. O numero de ovos postos pelas fêmeas desta classe é, de modo geral, muito mais reduzido que nos vertebrados inferiores. Em compensação, assegura-se-lhes melhor defesa contra os agentes destruidores. A correlação se mostra verdadeira, ainda, dentro da propria classe: quanto mais exposta a ninhada, tanto maior a quantidade de ovos. A regra prevalece tambem na relação inversa entre a rapidez de desenvolvimento dos filhos e a sègurança do ninho, e até mesmo entre o arranjo deste e a forma dos ovos. Por fim, a casca calcárea integra esse feliz sistema de proteção natural e automática da prole.

Tudo conspira, até aqui, para que as aves imitem os répteis, na indiferença pela paternidade: o ninho, a forma do ovo, a casca calcárea. Mas duas condições especiais, duas exigências imperiosas da nova geração estabelecem um vínculo poderoso entre pais e filhos: uma, é a necessidade de temperatura elevada e constante para a incubação; outra, é a relativa longura da infância. Essas duas condições, impondo ao casal uma demorada assistencia, geram, as reações da paternidade e da maternidade, e, por sobre isto, influem favoravelmente no sentido da monogamia.

Mas examinemos em especial, de acordo com a restrição que nos impuzemos, apenas o papel desempenhado pelo pai. 
Em certas espécies, - aliás raras, adverte Lespinas, -o macho não se liga à família: logo após o ato sexual, afasta-se da fêmea e vai em busca de novas aventuras. Acha-se neste grupo o famoso cuco, cuja vida é a menos familiar possivel. $O$ macho anda de conquista em conquista, sem nunca se fixar. A fêmea põe - dia sim, dia não - até uns vinte ovos; mas cada um no ninho de outro passaro, aproveitando a ausência dos proprietários e tendo o cuidado de tirar préviamente um dos ovos que ali encontre. 0 ovo do cuco é assim chocado por estranhos, e quando o filhote rompe a casca, como é maior e mais forte que os companheiros de ninhada, não tarda em expulsá-los e ficar senhor da situação (16).

Em outras espécies, como as de alguns galináceos, o macho deixa a fêmea desde o início da incubação, mas volta à família assim que os filhos nascem. Volta e assume o papel de pai e de chefe autoritário (17).

No terceiro grupo, afinal, está a grande maioria das aves. Aves monogâmicas, de fidelidade conjugal satisfatória, e cujo macho colabora com a fêmea na feitura do ninho, na incubação dos ovos e na proteção dos filhotes. São tão conhecidos os fatos desta natureza que nos dispensamos de referir casos concretos (18).

Nas aves, pela primeira vez aparece uma nova modalidade de ação dos pais sobre os filhos: a educação. Alguns pais (óra a fêmea, óra o macho), além de protegerem e alimentarem os filhos, procuram transmitir a estes, metódica

(16) CABrera (ANGEL) - Historia Natural. Instituto Gallach, Barcelona, 1925, vol. I, pag. 215.

(17) Espinas (Alfred) - Op. cit. pag. 338.

(18) Vale a pena reproduzir aqui, a título de curiosidade, o que conta um grave e moderno livro de Historia Natural, a propósito de uma colaboração original de "Ploceus baya", pássaro da India. Quando a fêmea começa a pôr, o macho para celebrar o acontecimento, ilumina interiormente o ninho, pregando nas respectivas paredes pequenos pelotes de barro, nos quais fixa vagalumes. A seguir, faz a mesma coisa no lado de fora, e assim, durante a noite, no meio da obscuridade da selva, o ninho surpreende pela fosforecência de suas luminarias vivas. 
e sistematicamente, a sua experiência de adultos. Dão-lhes áulas praticas de vôo, de natação, de caça. A pedagogia adotada é das mais modernas. Consiste em colocar alunos diante de "situações reais" (lançar, por exemplo, o filhote na agua, para que aprenda a nadar); ou em "motivar" a aprendizagem, acenando com o alimento afim de que o pequeno se decida a voar (19). Mas não exageremos: tudo se mantem dentro dos limites de um modesto e tímido ensáio. A verdadeira educação, - essa poderosa forma de interferência da geração adulta sobre a vida da nova geração, — só irá ser realmente explorada muito mais tarde, por um mamífero bípede do fim da era terciária, - o homem.

As aves, em suma, com um regime familiar semelhante ao do homem civilizado, e por circunstâncias de natureza biológica, entre as quais se salientam a necessidade de incubação dos ovos em temperatura constante e a longa duração da infância, põe-nos diante dos olhos, ainda que em escala reduzida, todas as modalidades da ação protetora da geração adulta sobre os filhos. $\mathrm{E}$ em quasi todas as espécies, o pai colabora neste trabalho com assiduidade e eficiência. A isto corresponde (causa ou efeito?) uma economia genética extraordinária, pois a fraca prolificidade das aves (em comparação com os vertebrados inferiores) nem lhes prejudica a natalidade nem lhes impõe o sacrifício de uma mortalidade infantil onerosa para a espécie.

\section{A situação do pai entre os mamíferos}

A incubação do ovo dos mamíferos se efetua, não mais no meio exterior, mas dentro do próprio organismo materno. A amamentação, em seguida, prolonga ainda a intimidade entre a mãe e os filhos. Estas duas circunstâncias vieram, de uma parte, robustecer os vínculos da maternidade, e, de outra, afrouxar os da paternidade; de modo que em

(19) Thомsom E Geddes - Life, N. York e Londres, s/d., I vol., pag. 554 . 
geral os mamíferos são excelentes mães e pessimos pais. Só nas mais altas espécies da classe é que o marido aparece colaborando na proteção da prole.

O ritmo da atração sexual permite distinguir, entre os mamiferos, dois grupos: de um lado, os que apresentam um periodo de frigidez sexual (anoestrus) mais ou menos prolongado, interrompido por curto período de cio; de outro, os que quasi sem interrupção sentem as impulsões sexuais.

Os primeiros, - a grande maioria, - são mamíferos inferiores. Na época do amor, cada sexo procura o sexo oposto; mas, logo após, a união se desfaz, machos e fêmeas se separam ou se tornam indiferentes. Em tais mamíferos, não se constitue propriamente uma família, pois as ligações duradouras se estabelecem unicamente entre mãe e filhos. 0 pai figura apenas como reprodutor.

O grupo de atração sexual permanente, que abrange os macacos e os antropóides, forma verdadeiras famílias: pais e mães ligados pelo atrativo sexual; filhos ligados às mães e, secundariamente, aos pais. "A unidade fundamental das sociedades de macacos e de antropoídes é o grupo de familia, consistindo em um chefe e seu harem, ligados entre si essencialmente pelo interesse do macho pelas fêmeas e pelo interesse comum em relação aos filhos" (20).

Afirmou-se reiteradamente que os antropóides (chimpamzé, gorila) são monogâmicos. Westermarcik foi mesmo buscar nessa afirmativa o apôio biológico para a monogamia humana. Reichnow afirma que o gorila não é poligâmico, mas monogâmico, e que a união matrimonial dura anos seguidos. Numerosos autores, no entretanto, citados por $\mathrm{Zu}-$ ckermann (Barns, Burbridge, Akeley, Jenirs, Chorley, Dyce, Sharpe) asseguram que o gorila é poligâmico. Na Uganda, Chorley viu uma família de gorilas composta de um adulto macho, três adultos fêmeas e dois jovens. $\mathrm{O}$ macho, já grisalho, era ciumento e irascivel, maltratando duramente as fêmeas. Estas, contudo, pareciam dedicar-lhe afei-

(20) Zuchermann (Dr. S.) - La Vie Sexuelle et Sociale des Singes, trad. fr., Paris, s/d., pag. 245. 
ção e repeliam os galanteios de dois outros machos. Aliás, como pondera ZuckermanN, nada impede que haja dois regimes: a maior ou menor facilidade no recrutamento de companheiras permitirá a uns a poligamia, obrigando outros a contentar-se com uma só esposa.

Entre os macacos inferiores, o macho não revela grande ternura nem pela esposa nem pelos filhos. Certa vez, narra ZuckermanN, deu-se, no jardim zoológico, uma ração de bananas a uma família de macacos, que consistia em um macho, uma fêmea e um recemnascido. O macho se apoderou de tudo, guardando uma parte na boca e pondo o resto sob seus pés. Um casal de babuinos estava engaiolado com um filho de poucos mezes, no parque da senhora Abreu, em Cuba. O pai se mostrava tão mau para o filho, que foi preciso separá-los (21). Aliás, o que os machos fazem às fêmeas, neste particular, as mães fazem por sua vez aos filhos, arrancando-lhes das mãos os alimentos a eles oferecidos. O que não as impede de amamentar carinhosamente.

Os antropoídes, - “quasi humanos" - são mais paternais. Mas pouco.

No chimpamzé, a gestação parece ser igual à da especie humana: nove mezes. A mã̉e amamenta o filho alguns mezes, ou mesmo até um ou dois anos. O filho fica com a família pouco mais que isso. Quando o filho nasce, "tudo depõe em favor de uma atitude do pai e da mãe adequada à situação, e não menos demonstrativa de impulsos altruísti$\cos$ e de devotamento do que em relação aos recemnascidos da nossa especie" A mãe ensina a andar, e o filho completa a aprendizagem aos seis meses. No inicio da infância, o pai colabora na criação e educação do filho. "O pai é o elemento progressivo do grupo; a mãe é o elemento conservador", - diz Yerkes, numa linguagem ainda à moda antropomórfica. O pai se encarrega principalmente da secção de jogos e da educação física; a mãe, do refeitório. Mas a

(21) Yerkes (Robert M.) - Almost Human, N. York, 1925, pag. 126. 
ternura do pai diminue rapidamente, e dentro em pouco sua atuação é no sentido de enxotar o filho do lar (22).

A proposito do gorila, as informações são precárias. ReIchNow afirma que os filhos ficam em companhia dos pais talvez mesmo até constituirem familia.

Em suma, as condições biológicas da grande maioria dos mamiferos - incubação do ovo dentro do organismo da fêmea, aleitamento, laços frouxos da família, - si concorrem, de um lado, para acentuar as funções maternais, conspiram, de outro, em sentido oposto, contra a paternidade. Só entre os antropoídes, de regime familiar coeso, de filhos com infancia prolongada, é que encontramos pais realmente eficientes, como defensores e, de certo modo, educadores dos filhos.

\section{Considerações finais}

Terminemos, enfim, com algumas considerações de ordem geral, este primeiro trabalho.

A conservação dos novos indivíduos, incessantemente produzidos pela geração, realiza-se, na natureza, atravez de processos extremamente variados. Nos seres mais baixos da escala animal, bastam, para esse fim, os recursos inerente ao próprio ovo, circunstância essa a que se agrega a inexistência de uma fase de crescimento e adaptação post-natais, - ou infância. Quando os seres se tornam mais complexos, as condições iniciais dos seus produtos impõem uma intervenção protetora, direta, da parte da geração adulta.

A ação protetora é, em determinados casos, exercida por elementos não reprodutores da espécie, os quais, graças a uma verdadeira castração biológica, se especializam no exercício daquele trabalho. Na maioria dos casos, porém, os próprios genitores, - óra o genitor feminino, em alguns raros casos o genitor masculino, e, nas espécies mais elevadas, os dois elementos do casal.

(22) Yerkes (Robert M.), - op. cit. pag. 137. 
Pai, no sentido estritamente biológico, é o genitor masculino, o fornecedor do espermatozóide para a reprodução. Condições diversas, porém, obrigam a agregar a essa noção nuclear alguns outros elementos, que integram o conceito de paternidade não só em relação à espécie humana como aos vertebrados mais altos da escala zoológica: o pai é, adicionalmente, quem abriga, defende, alimenta e educa.

$O$ advento do pai, como simples genitor, representa um aperfeiçoamento no processo de reprodução e um benefício para a espécie. A sua intervenção como colaborador na proteção da prole, alem de contribuir vantajosamente para a conservação da espécie, dá maior coesão ao grupo familiar.

Fatos estritamente biológicos condicionam a fixação do pai na familia: a necessidade de uma proteção prolongada, - pre ou post-natal _, e a possibilidade de ser essa proteção exercida pelos dois genitores. É nas aves que os dois fatos se reunem em circunstâncias mais favoraveis ao desenvolvimento da função familiar da paternidade.

Nos mamíferos inferiores, a incubação interna do ovo, a existência de uma infância breve, precocemente agil, e a periodicidade sexual, são fatores pouco propícios à colaboração protetora do pai. Nos antropóides, - e, mais ainda, no homem, - a longura da infância e, indiretamente, a atração sexual continua, constituem estimulos naturais à função adicional da paternidade. 